\title{
Research on Financial Stability and Risk Contagion*
}

\author{
Xiaoyu Liu \\ Harbin Finance University \\ Harbin, China
}

\begin{abstract}
The systematic study of financial risk contagion has an urgent need and far-reaching significance, which is not only conducive to revealing the transmission mechanism of financial crisis, thus conducive to the formulation and implementation of financial regulation and financial stability policies but also can improve the decision-making ability of micro-financial subjects in the new international environment.
\end{abstract}

Keywords-financial stability; risk of infection; financial globalization

\section{INTRODUCTION}

The emergence of financial contagion has posed new challenges for the country to maintain the stability of its financial system, and also had a profound impact on the decision-making of micro-financial subjects. With the deepening of financial integration, the high interconnectedness of countries allowed the crisis to spread rapidly, creating new challenges for financial regulation; the diversification offered by international portfolios is also being eroded. At the same time, it is also the driver of the acceleration of financial risk contagion.

\section{RESEARCH ON FINANCIAL STABILITY}

Financial system is a stable dynamic system, the system is a dynamic process and information exchange with the environment energy, thus system always exist in the stable instability, under certain conditions, this unstable to enlarge, beyond the system remains stable in its original condition, system maintain its stability is destroyed, the ability of the system on the whole buckling, evolve to enter to a new steady state. The financial system is a complex and open giant system and a dissipative structure. From the perspective of system evolution, the stability of financial system has three characteristics: One is that there is no fluctuation in the equilibrium state; Second, in the linear non-equilibrium region close to the equilibrium state, fluctuations will only make the system state temporarily deviate, and this deviate state will continuously attenuate until disappear, and finally return to the original stable state; Third, in the non-linear region far from the equilibrium state, the system is in a dynamic equilibrium, at this time, a perturbation of the system will be amplified by the coherent

* Fund: Heilongijiang youth innovation talent training program project: Research on risk contagion and prevention and control strategy in financial network based on SIR and SIS combined model (Project Number: UNPYSCT-2018051); Research project of philosophy and social science in Heilongjiang province: results of risk contagion and simulation research in financial network based on SIRS model (Project Number: 18JYE660). effect, and it may become a macroscopic "giant fluctuation" of the whole, making the system enter an unstable state. So it jumps into a new stable ordered state.

Financial stability includes the stability of financial asset prices and financial institutions. The stability of financial institutions often refers to the stability of the banking system. The financial crisis refers to that when the banking crisis reaches a serious level, a country's financial market fails and its basic economic structure, production and consumption are also adversely affected. Kingdleberger (C. P.) according to goldsmith's definition, financial crisis refers to a crisis in the social financial system, which is mainly manifested in all or most of the financial indicators, such as interest rates, securities, real estate and land prices, and the number of business and financial institution failures, etc., and deteriorates sharply, briefly and in a super-cycle in the short term. As can be seen from the definition, the financial crisis has two meanings. The first is that the deterioration covers all or most of the financial sector; second, the financial deterioration during the crisis was sudden.

\section{CAUSES OF FINANCIAL RISK CONTAGION}

Financial risk contagion is a spreading phenomenon of financial crisis in the international financial market. With the deepening of world economic and financial integration, financial contagion effect is also expanding. Contagion is an important feature of financial market risks. It is particularly destructive and serious enough to cause a crisis in the financial system. Financial risk contagion effect refers to the financial crisis in one country spreads to other countries in a domino effect. Direct contagion among financial institutions means that once a financial institution goes bankrupt, other financial institutions directly connected with the financial institution will suffer from debt default losses, thus leading to further spread of bankruptcy crisis. Indirect transmission involves transmission mechanisms other than direct transmission; it is mainly caused by the lack of market confidence and the spiral decline of asset prices. The causes of financial risk contagion in China are complex, which are mainly analyzed from the three aspects of enterprises, Banks and the government's own behaviors.

\section{A. The Financial System Lacks Perfect Micro Foundation of Modern Enterprise System}

The lack of perfect modern enterprise system leads to the abnormal behavior of institutional fund raisers and institutional investors in the financial market. As it can be 
known, property right is the right that benefits or damages a person, and it reflects the definition of mutual interests between people. By grant property right is in multiple level delegates. Agency relationship has failed to effectively define clear boundaries between different stakeholders interests, make a lot of state-owned enterprises and some failed to form the effective corporate governance structure of listed companies, the state-owned assets of the principal and the agent asked failed to form effective incentive and supervisory mechanism, on the one hand, the operator controls the enterprise owners and bank into all of the resources, On the other hand, the operator controls all the information about these resources running status. Because one agent of state-owned assets in terms of rights, benefits, and responsibility highly asymmetric, it makes them blindly pursue their own self-interest or a unit, as well as the misuse or misappropriation of state assets, and the bank on the safety and liquidity of capital losses. Debtors are not, in effect, responsible for their debts. They can survive on how much they owe and survive on how much they spend. At present, many people believe that one of the main reasons for the high debt of enterprises is the poor economic performance of enterprises, but it is difficult for people to explain why enterprises with continuous profits are also in the high debt ranks. In fact, when an enterprise is in a risky capital structure with high debt, no matter how its operating status is, it will not change the fact that it has high debt and defaults on debt repayment. The reason why Chinese enterprises have such a high debt ratio lies in the soft budget constraint of corporate behavior.

In the context of a more complete market economy and clearly defined property rights, in consideration of the pressure of debt repayment and the legal consequences of insolvency, in order to protect the rights and interests of the owners, the owners will not allow the operators to borrow money rashly. Creditors usually refuse to provide funds for risks beyond the owners' proven ability to bear; Restricted by creditors and owners, and taking into account their own interests; operators will not risk bankruptcy and debt repayment. It is precisely because Chinese state-owned enterprises do not have such constraints and pressures that they are never afraid of debt financing in the choice of capital structure. Due to the lack of perfect micro-foundation of modern enterprise system and lack of clear property rights and hard budget constraints, this has led to the distortion of the behavior of the enterprises themselves of the market subjects, making the financial industry unable to obtain a solid foundation for development on the basis of improving efficiency. As a result, the risks gradually accumulate and the non-performing loans of banks increase year by year.

\section{B. The Subject of Risk Prevention Is Unclear}

At present, there is a strange phenomenon in the prevention of financial risks. The central bank is very concerned about financial risks and takes various measures to prevent them, but some commercial Banks do not pay enough attention to it. The reason is that commercial Banks do not really realize that they are the main body to prevent financial risks. In theory, investors are very clear, in the event of financial risk can lead to capital losses and the loss of bank credit, investors will request strict risk prevention to operator, and make corresponding system arrangement, on the other hand, out of respect for their own interests as the operator will also spare no effort to lower risk, However, the right of management and the right of ownership of Chinese Banks are ambiguous. The misunderstanding is that the ultimate undertaker of financial risks is the central bank. Therefore, the main body of prevention is the central bank.

\section{Unclear Subjects Who Bear the Cost of Financial Risks}

According to the requirements of accounting standards, when a bank suffers a loss, it should first be the investor who bears the loss, offset the loss with capital equity, and then the depositor and other creditors share the residual loss. The operator seems to have no risk responsibility at all. Because most Banks in China are invested by the state, the government not only bears the capital loss that should be borne by investors, but also bears the risk that should be borne by depositors, other creditors and even operators. As a result, the operators of the bank run the bank, but do not bear the corresponding risk cost. Low operating performance rhyme, operator behavior variation becomes inevitable.

\section{ChallENGES TO FINANCIAL STABILITY IN THE CONTEXT OF FINANCIAL RISK CONTAGION}

Maintaining a stable financial system is crucial, and the experience of East Asian countries and regions actually shows that a "good" financial system in a developing country, on the one hand, should be able to maximize the amount of Chinese and foreign savings and convert those savings into investment. On the other hand, the quality of investment can be guaranteed, thus achieving a balance between promoting investment increase and ensuring investment quality. If the quality of investment is high and the amount of investment is not large enough, it will affect the speed of economic growth. If the amount of investment increases a lot and the quality of many investments is not high, economic growth will not be sustainable. To maintain the stability of the financial system is not only the need to ensure the quantity and quality of investment, but also the need to share the benefits of capital flow people in the new situation of financial market globalization, as well as the need to strengthen the resistance to financial risk contagion in other countries. It can be seen that the emergence of financial contagion has posed new challenges for the country to maintain the stability of its financial system, and also had a profound impact on the decision-making of micro-financial subjects. Firstly, with the deepening of financial integration, the high correlation between countries makes the crisis spread rapidly, which brings new challenges to financial regulation. Second, the risk diversification offered by international portfolios is also being eroded. The fact that the instability of the Chinese financial system in some countries triggered a large number of sudden capital outflows, with disastrous consequences, shows that with financial markets already global, maintaining financial stability is harder and more important than ever. But in this regard, developing countries face many 
new challenges. The main performance is of the following two aspects.

\section{A. How to Ensure the Effective Utilization of Foreign Capital Flowing Through the Financial System}

Although in developing countries, as in Indonesia before the financial crisis, most of the external debt is borrowed directly by non-financial enterprises, in general, the external debt of the private sector of developing countries is utilized and distributed mainly through their financial systems. The stability of the Chinese financial system will also be threatened if this portion of the external debt is used inefficiently or if its repayment runs into obstacles. South Korea and Thailand had such problems before the financial crisis. South Korean financial institutions borrowed a large amount of foreign debt and lent it to the big chaebol with low investment efficiency. The bankruptcy and operational difficulties of the chaebol caused losses to the financial institutions closely related to them. Thailand's financial institutions borrowed a large amount of foreign debt for high-risk real estate investment and securities investment. The bursting of the real estate and stock bubble economy made these financial institutions in trouble. On the contrary, prudent financial institutions can act as a "floodgate" for foreign investors. When the inflow of foreign capital exceeds a certain limit and the utilization efficiency is reduced, the gate will control the flow of foreign capital or even automatically close to avoid new inflow of foreign capital. This role of financial institutions can actually be called the "first line of defense" to avoid financial crisis. The strength of this line of defense depends on the institutions' own organizational structure. The drive to control risk and their ability strikes a balance between profitability and soundness.

\section{B. Chinese Financial Institutions Are Facing Increased Competitive Pressure}

Accompanied by the globalization of the financial market, a large number of foreign-funded financial institutions have entered the Chinese financial market, and the barriers between Chinese residents and enterprises and foreign financial institutions have been removed. As a result, Chinese financial institutions are no longer the monopolistic intermediary organizations in terms of mobilizing and distributing Chinese savings. If Chinese financial institutions do not have safety, service quality and cost, it will be difficult to survive under the competitive pressure of foreign financial institutions. The reality is that financial institutions in developed countries often have advantages in organizational management, risk control and credibility that are hard to match for financial institutions in developing countries. Before introducing competition from foreign financial institutions, it is helpful to create a level playing field among Chinese financial institutions to improve their international competitiveness.

\section{CONCLUSION}

Visible, financial stability not only requires no big financial crisis, while the financial system itself can resist and absorb certain imbalance. Resisting the spread of the financial risk in the financial system exist imbalance may be hard to avoid certain limits. Finance system is the key to correcting imbalances, so it will be necessary to not make its cumulative expansion, so that it would endanger the whole system and the real economic growth of a well-functioning financial system. It will be necessary to prevent problems for systemic risk and be able to restore market equilibrium through self-correction market discipline.

\section{REFERENCES}

[1] Kasselaki, M. T. and A. O. Tagkalakis, 2013,"Financial Soundness Indicators and Financial Crisis Episodes", Bank of GreeceWorking Papers, No. 158.

[2] Claessens, S., H. Tong and S. J. Wei, 2012, "From the Financia Crisis to the Real Economy: Using Firm - level Data to Identify Transmission Channels", Journal of International Economics,88 (2): $375-387$

[3] Matesanza, D. and G. J. Ortegab, 2015, "Sovereign public debt crisis in Europe. A network analysis", Physica A: Statistical Mechanics and its Applications, 436( 15) : 756-766.

[4] Mink, M. and J. D. Haan, 2013, "Contagion during the Greek Sovereign Debt Crisis", Journal of International Money and Finance, 34: $102-113$. 